\title{
Association Between Transcription Factor 7-Like-2 Polymorphisms and Type 2 Diabetes Mellitus in a Ghanaian Population
}

Christian Obirikorang ${ }^{1}$, Evans Asamoah $\mathrm{Adu}^{1}$, Enoch Odame Anto ${ }^{2,3^{*}}$, Emmanuel Acheampong ${ }^{2}$, Lawrence Quaye ${ }^{4}$, Brodrick Yeboah Amoah ${ }^{5}$, Max Efui Annani-Akollor ${ }^{1}$, Aaron Siaw Kwakye ${ }^{6}$, Foster Fokuoh $^{6}$, Michael Appiah ${ }^{1}$, Eric Nana Yaw Nyarko ${ }^{1}$, Freeman Aidoo ${ }^{1}$, Eric Adua ${ }^{2}$, Ebenezer AfrifaYamoah $^{7}$, Lois Balmer ${ }^{2}$, Wei Wang ${ }^{2,8}$

${ }^{1}$ Department of Molecular Medicine, School of Medicine and Dentistry, Kwame Nkrumah University of Science and Technology, Kumasi, Ghana

2 School of Medical and Health Sciences, Edith Cowan University, Perth, Australia

${ }^{3}$ Department of Medical Diagnostics, Faculty of Allied Health Science, Kwame Nkrumah University of Science and Technology, Kumasi, Ghana

${ }^{4}$ Department of Biomedical Laboratory Sciences, School of Allied Health Sciences, University for Development Studies, Tamale, Ghana

${ }^{5}$ Chemical Pathology Unit, Medical Laboratory Sciences Department, School of Basic and Allied Health Sciences, University of Ghana, Accra, Ghana

${ }^{6}$ Eastern Regional Hospital, Koforidua, Ghana

${ }^{7}$ School of Science, Edith Cowan University, 270 Joondalup Drive, Western Australia

${ }^{8}$ Centre for Precision Health, ECU Strategic Research Centre, Edith Cowan University, Perth, Australia

\section{*Corresponding authors}

Enoch Odame Anto

Department of Medical Diagnostics

Kwame Nkrumah University of Science and Technology

Email: odameenoch@yahoo.com 


\begin{abstract}
Type-2 diabetes mellitus (T2DM) have been strongly associated with single nucleotide polymorphisms (SNPs) in the TCF7L2 gene. This study investigated the association between rs12255372, rs7903146 and T2DM in a Ghanaian population. A case-control study design was used for this study. A total of 106 T2DM patients and 110 control participants were selected. Basic data collected included body mass index, blood pressure and socio-demographics. Fasting blood samples were collected and used for serum lipid analysis, HbAlc, plasma glucose estimation and DNA extraction. Common and allelespecific primers were designed for genotyping using the Modified Tetra-Primer Amplification assay. Associations were evaluated using logistic regression models. The rs7903146 risk variant was significantly associated with 2.16 vs 4.06 increased odds for T2DM in patients $<60$ years vs $\geq 60$ years. Both rs7903146 and rs12255372 are significantly associated with increased odds of T2DM in women, overweight/obese; T2DM negative family history (T2DM-NFH) and low-HDL-C. In a multivariate model, rs7903146 but not rs12255372 was significantly associated with 2.18, 5.01 and 2.25 increased odds of T2DM, under the codominant, recessive and additive model, respectively $(p<0.05)$. The association between rs7903146 and rs 12255372 with T2DM is more highly associated in a subgroupwomen and those with T2DM-NFH, yet have cardiometabolic risk.
\end{abstract}

Keywords: TCF7L2, type 2 diabetes mellitus, cardiometabolic risk factors, single nucleotide polymorphisms

Abbreviations: DNA- Deoxyribonucleic Acid; GIP-Gastric inhibitory polypeptide; GLP-1- Glucagonlike peptide 1; HbAlc-Glycated haemoglobin; LD-Linkage disequilibrium; MAF: Minor allele frequency; MTPA- Modified tetra-primer amplification; SNP-Single nucleotide polymorphism; SSAsub-Saharan Africa; T2DM-Type-2 diabetes mellitus; TCF7L2- Transcription factor 7 like 2 


\section{Background}

Diabetes continues to rise in prevalence across the globe. Alarmingly, 4 out of 5 people with diabetes live in low-middle-income countries (LMIC), where adequate resources for diabetes management are scarce [1]. According to the International Diabetes Federation (IDF) 2017, it is estimated that nearly half a billion of the world's population is living with diabetes [1]. Khan, Hashim et al., (2) reported that 462 million individuals are affected by diabetes, corresponding to $6.28 \%$ of the world's population. This figure is projected to reach 7079 individuals per 100,000 by 2030 , reflecting a continued rise across all regions of the world [2]. Due to the continues increase rate of diabetes worldwide, the 2030 projected rate is likely to be exceeded $[2,3]$. This leads to high mortality from diabetic complications including cardiovascular disease [4]. The alarming situation is that 174.8 million (45.8\%) of all diabetic cases, in adults, are undiagnosed with the most affected individuals from LMIC [5]. Thus, T2DM remains a threat to the world's population, even though there is increasing life-expectancy, which requires both public health and clinical care to prevent what is already a worldwide health crisis.

In Ghana, T2DM is prevalent among $6.46 \%$ [6] of the population, which is significantly greater than the 2017 International Diabetes Federation (IDF) estimation [1]. A number of factors including physical inactivity, poor diet, rapid urbanisation and ageing are common among people living with diabetes [7]. Besides these factors, T2DM has a strong genetic predisposition, taking the combination of inequalities across different populations, familial aggregation and concordance among monozygotic twins $[8,9]$. Specifically, in T2DM, these factors are closely related to the metabolic abnormalities that underline the conditions of impaired insulin action, obesity, increased endogenous glucose output, and insulin secretory dysfunction [10]. It is well-known that genes control and regulate glucose and metabolic homeostasis, which influence the digestion, absorption and metabolic processes of lipids and carbohydrates can initiate the major mechanisms in T2DM [11].

Genome-wide association studies (GWAS) have identified genetic variants in these metabolic pathways which would provide new ways to understand the mechanism of T2DM [12, 13]. Among these genetic risk variants, the transcription factor 7-like 2 (TCF7L2), represent the most identified and promising T2DM candidate gene to date [14]. Variants in this gene has been identified with the strongest association with T2DM [14-19]. Since a common microsatellite in the TCF7L2 gene region, DG10S478, (containing SNPs rs7903146 and rs12255372) was found to be associated with T2DM [20], the finding has been convincingly replicated in different population groups. Using non-coding SNPs in strong linkage disequilibrium with DG10S478 [16, 21, 22], an estimated population attributable risk of $17-28 \%$ has been established.

TCF7L2 encodes a high mobility group of box-containing transcription factors, which is involved in the Wnt signalling pathway [17]. The Wnt signalling pathway represents one of the pancreatic beta 
cell's important developmental and regulatory mechanism, which is critical in determining its fate, proliferation, polarity, and apoptosis during embryonic development and adult tissue homeostasis [20]. Risk alleles of TCF7L2 have been strongly associated with impaired insulin secretion/beta-cell function and T2DM [23-25]. Likewise, TCF7L2 has been shown to mediate regulation of glucagon-like peptide1 expression, which represents a mechanism by which alteration of this gene influences susceptibility to T2DM [24]. There has been only a limited number of studies within the African Context, which makes it difficult to pool the effects and homogeneity of variants associated with T2DM [26]. Thus, replication studies are needed to understand the effect of these gene variants on T2DM. This study investigated the association between TCF7L2 gene polymorphisms and T2DM in a Ghanaian population.

\section{Results}

\section{Characteristics of the study participants}

Table 1 shows the socio-demographic characteristics of the study participants. The proportion of participants aged 60 and above was significantly higher in the cases compared to the controls $(31.1 \%$ vs $17.3 \%, \mathrm{p}=0.017$ ). Most of the T2DM participants had a T2DM positive family history (T2DM-PFH) than the control group $(42.5 \%$ vs $11.8 \%, \mathrm{p}<0.001)$. Aside from LDL-C ( $\mathrm{p}=0.288)$, the mean TC, TG, HDL-C and LDL-C significantly differed between the cases and control participants $(p<0.05)$. The proportion of cases vs controls with high TC (12.3\% vs 5.6\%, p=0.077), overweight ( $40.6 \%$ vs $35.5 \%$, $\mathrm{p}=0.441)$ and obese $(27.4 \%$ vs $19.1 \%, \mathrm{p}=0.149)$ did not differ significantly. High BP, atherogenic dyslipidaemia and Metabolic Syndrome (MetS) were higher in the cases than the controls (p-value $<0.001)$. 
Table 1: Comparison of demographic variables, anthropometric measures and biochemical profiles between the cases and controls

\begin{tabular}{lccc}
\hline Variables & $\begin{array}{c}\text { Cases } \\
(\mathbf{N}=\mathbf{1 0 6})\end{array}$ & $\begin{array}{c}\text { Controls } \\
(\mathbf{N}=\mathbf{1 1 0})\end{array}$ & P-value \\
\hline Sex & & & \\
Male & $46(43.4)$ & $37(33.6)$ & 0.140 \\
Female & $60(56.6)$ & $73(66.4)$ & \\
Family history of T2DM & & & \\
No & $61(57.7)$ & $97(88.2)$ & \\
Yes & $45(42.5)$ & $13(11.8)$ & $<\mathbf{0 . 0 0 1}$ \\
Age (years) & $53.90 \pm 12.31$ & $45.80 \pm 12.14$ & $<\mathbf{0 . 0 0 1}$ \\
$<60$ years & $73(68.9)$ & $91(82.7)$ & \\
$\geq 60$ years & $33(31.1)$ & $19(17.3)$ & $\mathbf{0 . 0 1 7}$ \\
Anthropometric variables\# & & & \\
BMI (Kg/m $\left.{ }^{2}\right)$ & $28.18 \pm 5.53$ & $26.10 \pm 4.41$ & $\mathbf{0 . 0 0 2}$ \\
Systolic BP (mmHg) & $133.35 \pm 19.76$ & $121.25 \pm 18.41$ & $<\mathbf{0 . 0 0 1}$ \\
Diastolic BP (mmHg) & $83.68 \pm 11.74$ & $76.22 \pm 11.17$ & $<\mathbf{0 . 0 0 1}$ \\
Biochemical parameters\# & & & \\
Triglycerides (mmol/l) & $1.69 \pm 0.64$ & $1.29 \pm 0.50$ & $<\mathbf{0 . 0 0 1}$ \\
T. Chol (mmol/l) & $5.25 \pm 1.03$ & $4.65 \pm 1.06$ & $<\mathbf{0 . 0 0 1}$ \\
HDL-C(mmol/l) & $0.99 \pm 0.24$ & $1.23 \pm 0.27$ & $<\mathbf{0 . 0 0 1}$ \\
LDL-C (mmol/l) & $3.44 \pm 0.95$ & $3.32 \pm 0.72$ & 0.288 \\
FPG (mmol/l) & $8.72 \pm 4.66$ & $4.85 \pm 0.91$ & $<\mathbf{0 . 0 0 1}$ \\
HbA1c (\%) & $6.99 \pm 1.87$ & $4.83 \pm 0.60$ & $<\mathbf{0 . 0 0 1}$ \\
Cardiometabolic factors & & & \\
High BP & $36(34.0)$ & $10(9.1)$ & $<\mathbf{0 . 0 0 1}$ \\
High TC & $13(12.3)$ & $6(5.5)$ & 0.077 \\
High TG & $61(57.5)$ & $16(14.5 \%)$ & $<\mathbf{0 . 0 0 1}$ \\
Low HDL-C & $81(76.4)$ & $52(47.3)$ & $<\mathbf{0 . 0 0 1}$ \\
High LDL-C & $64(60.4)$ & $36(32.7)$ & $<\mathbf{0 . 0 0 1}$ \\
Atherogenic dyslipidaemia & $44(41.6)$ & $5(4.5)$ & $<\mathbf{0 . 0 0 1}$ \\
Overweight & $43(40.6)$ & $39(35.5)$ & 0.441 \\
Obesity & $29(27.4)$ & $21(19.1)$ & 0.149 \\
MetS & $70(66.0)$ & $14(12.7)$ & $<\mathbf{0 . 0 0 1}$ \\
\hline All & & & \\
\hline
\end{tabular}

All values are presented as frequency and percentages unless stated. \# Values are presented as mean and standard deviations. P-values highlighted are statistically significant $(<0.05)$

\section{Genotype and allele frequencies of $T C F 7 L 2$ gene polymorphism}

The genotype and minor allele frequencies (MAF) of rs7903146 and rs12255372 of the TCF7L2 gene are shown in Table 2. The MAF of rs7903146 was 50.5\% and $33.3 \%$ among cases and control participants, with statistically significant differences $(\mathrm{p}=0.011)$. The homozygote recessive allele (TT) of rs7903146, was more prevalent among cases than control participants $(13.2 \%$ and $4.5 \%, p=0.024)$. The MAF of rs 12255372 was $24.1 \%$ among cases, which is significantly higher $(\mathrm{p}=0.013)$ than that of controls $(14.2 \%)$. The GG genotype $(\mathrm{p}=0.013)$ and GT genotype $(\mathrm{p}=0.023)$ but not the TT genotype $(\mathrm{p}=0.501)$ of rs 12255372 was disproportionately distributed between the cases vs control participants. 
Table 2: Distribution of $T C F 7 L 2$ gene polymorphism in cases and control participants

\begin{tabular}{|c|c|c|c|c|c|c|c|}
\hline \multirow[t]{3}{*}{$\overline{\text { SNP }}$} & \multicolumn{3}{|c|}{ Controls $(n=110)$} & \multicolumn{3}{|c|}{ Cases $(n=106)$} & \multirow{3}{*}{ P-value } \\
\hline & \multirow[t]{2}{*}{$\%$} & \multicolumn{2}{|c|}{ Allele frequency } & \multirow[t]{2}{*}{$\mathrm{N}(\%)$} & \multicolumn{2}{|c|}{ Allele frequency } & \\
\hline & & $\mathrm{C}$ & $\mathbf{T}$ & & $\mathrm{C}$ & $\mathbf{T}$ & \\
\hline rs7903146 & & 0.667 & $\underline{0.333}$ & & 0.495 & $\underline{0.505}$ & 0.011 \\
\hline $\mathrm{CC}$ & 49 (44.5) & & & $26(24.5)$ & & & 0.002 \\
\hline CT & $56(50.9)$ & & & $66(62.3)$ & & & 0.092 \\
\hline \multirow[t]{2}{*}{ TT } & $5(4.5)$ & & & $14(13.2)$ & & & 0.024 \\
\hline & & $\mathrm{G}$ & $\mathrm{T}$ & & $\mathrm{G}$ & $\mathrm{T}$ & \\
\hline rs12255372 & & 0.857 & $\underline{0.143}$ & & 0.759 & $\underline{0.241}$ & 0.068 \\
\hline GG & $81(73.6)$ & & & $61(57.5)$ & & & 0.013 \\
\hline GT & $24(21.8)$ & & & $38(35.8)$ & & & 0.023 \\
\hline TT & $5(4.5)$ & & & $7(6.6)$ & & & 0.501 \\
\hline
\end{tabular}

Highlighted P-values are statistically significant.

\section{Linkage disequilibrium between rs7903146 and rs12255372}

The linkage disequilibrium (LD) and pairwise LD coefficients $\mathrm{r}^{2}$ and $\mathrm{D}^{\prime}$ between rs12255372 and rs7903146 demonstrated that the alleles for the rs7903146 (C>T) and rs12255372 (G>T) SNPs are weakly associated $\left(D^{\prime}=\mathbf{0 . 0 2 1} ; \mathbf{r}^{2}=\mathbf{0 . 0 0 0 1}\right)$.

\section{Association between TCF7L2 polymorphisms and T2DM}

There is an association between rs12255372 and rs7903146 with T2DM (Table 3). Here rs7903146 was significantly associated with increased risk of T2DM in the codominant model $(\mathrm{OR}=2.22, \mathrm{p}=0.008)$, recessive model $(\mathrm{OR}=5.28, \mathrm{p}=0.004)$ and additive model $(\mathrm{OR}=2.47, \mathrm{p}=0.002)$. After adjusting the model for age, sex, family history, high cholesterol and overweight/obesity, rs7903146 was still associated with $\mathrm{T} 2 \mathrm{DM}$; additive $(\mathrm{OR}=2.25, \mathrm{p}=0.003)$, recessive $(\mathrm{OR}=4.92, \mathrm{p}=0.011)$ and codominant $(\mathrm{OR}=2.29, \mathrm{p}=0.019)$. $\mathrm{rs} 12255372$ was significantly associated with $\mathrm{T} 2 \mathrm{DM}$ under the codominant $(\mathrm{OR}=$ 2.10, $\mathrm{p}=0.017)$ and additive model $(\mathrm{OR}=1.70, \mathrm{p}=0.026)$ but not the recessive model $(\mathrm{OR}=1.86$, $\mathrm{p}=0.309$ ). After adjustment for confounders, no association was found between rs 12255372 and T2DM ( $\mathrm{p}>0.05$ ). In a multivariate model, $\mathrm{rs} 7903146$ but not rs 12255372 was significantly associated with 2.18 , 5.01 and 2.25 increased odds of T2DM under the codominant, recessive and additive model respectively $(\mathrm{p}<0.05)$. 
Table 3: Association between rs12255372 and rs7903146 and T2DM

\begin{tabular}{llclllll}
\hline SNPs & \multicolumn{2}{c}{$\begin{array}{c}\text { Crude model } \\
\text { OR (95\% CI) }\end{array}$} & $\begin{array}{c}\text { P- } \\
\text { value }\end{array}$ & OR (95\% CI) & $\begin{array}{c}\text { Adjusted model } \\
\text { Palue }\end{array}$ & OR (95\% CI) & $\begin{array}{c}\text { P- } \\
\text { value }\end{array}$ \\
\hline rs7903146 & & & & & & \\
Codominant & $2.22(1.23-4.02)$ & $\mathbf{0 . 0 0 8}$ & $2.29(1.14-4.58)$ & $\mathbf{0 . 0 1 9}$ & $2.18(1.08-4.39)$ & $\mathbf{0 . 0 3 0}$ \\
Recessive & $5.28(1.71-16.27)$ & $\mathbf{0 . 0 0 4}$ & $4.92(1.45-16.72)$ & $\mathbf{0 . 0 1 1}$ & $5.01(1.44-17.44)$ & $\mathbf{0 . 0 1 1}$ \\
Additive & $2.47(1.38-4.42)$ & $\mathbf{0 . 0 0 2}$ & $2.25(1.32-3.83)$ & $\mathbf{0 . 0 0 3}$ & $2.25(1.31-3.84)$ & $\mathbf{0 . 0 0 3}$ \\
\hline rs12255372 & & & & & & \\
Codominant & $2.10(1.14-3.87)$ & $\mathbf{0 . 0 1 7}$ & $1.80(0.92-3.52)$ & 0.085 & $1.72(0.86-3.43)$ & 0.124 \\
Recessive & $1.86(0.56-6.14)$ & 0.309 & $1.13(0.29-4.43)$ & 0.859 & $1.26(0.32-5.044)$ & 0.742 \\
Additive & $1.70(1.06-2.71)$ & $\mathbf{0 . 0 2 6}$ & $1.40(0.83-2.36)$ & 0.206 & $1.39(0.82-2.38)$ & 0.222 \\
\hline
\end{tabular}

OR-Odds ratio; CI- confidence interval. highlighted $P$-values are statistically significant.

Table 4 demonstrates an association between rs12255372 and rs7903146 polymorphisms and T2DM within subcategories. The rs7903146 polymorphisms (C>T) was significantly associated with $2.16 \mathrm{vs}$ 4.06 increased odds ratio of T2DM in persons aged below 60 years vs persons aged above 60 -years. The rs7903146 (C>T) was significantly associated with increased odds ratio of T2DM in both normal weight $(\mathrm{OR}=2.52,95 \% \mathrm{CI}: 1.02-6.26)$ and overweight/obese $(\mathrm{OR}=2.15,95 \% \mathrm{CI}: 1.01-4.56)$ individuals; normal $\mathrm{BP}(\mathrm{OR}=2.93,95 \% \mathrm{CI}$ : 1.51-5.66); T2DM negative family history (T2DM-NFH) $(\mathrm{OR}=2.71,95 \% \mathrm{CI}: 1.35-5.45)$; females $(2.71,95 \% \mathrm{CI}: 1.30-5.65)$; elevated $\mathrm{TG}(\mathrm{OR}=3.87,95 \% \mathrm{CI}$ : 1.2112.41) and low HDL-C (OR=2.95, 95\%CI: 1.40-6.24). On the other hand, rs $12255372(\mathrm{G}>\mathrm{T})$ was significantly associated with excess risk of T2DM among patients aged 60 and above $(\mathrm{OR}=52.45$, 95\%CI: 2.92-942.04); increased odds of T2DM among patients with low HDL-C (OR=2.35, 95\%CI: 1.10-5.00), overweight/obese $(\mathrm{OR}=2.43,95 \% \mathrm{CI}: 1.19-4.98)$, T2DM-NFH $(\mathrm{OR}=2.07,95 \% \mathrm{CI}$ : $1.04-$ $4.12)$ and females ( $\mathrm{OR}=2.34,95 \% \mathrm{CI}: 1.11-4.95)$. 
Table 4: Association between rs12255372 and rs7903146 polymorphisms and T2DM whiles keeping other metabolic risk factors as fixed

\begin{tabular}{|c|c|c|}
\hline & rs7903146 & rs12255372 \\
\hline Risk Factors & OR $(95 \%$ CI $)$ & OR $(95 \% \mathrm{CI})$ \\
\hline \multicolumn{3}{|l|}{$\overline{\text { Age }}$} \\
\hline$<60$ years & $2.16(1.11-4.22) *$ & $1.18(0.62-2.26)$ \\
\hline 60 and above & $4.06(1.25-13.19) * *$ & $52.45(2.92-942.04) * *$ \\
\hline \multicolumn{3}{|l|}{ Family history } \\
\hline NFH & $2.71(1.35-5.45) * *$ & $2.07(1.04-4.12) *$ \\
\hline PFH & $1.00(0.25-3.98)$ & $1.01(0.31-3.36)$ \\
\hline \multicolumn{3}{|l|}{ Sex } \\
\hline Male & $1.90(0.75-4.84)$ & $1.53(0.64-3.68)$ \\
\hline Female & $2.71(1.30-5.65) * *$ & $2.34(1.11-4.95) * *$ \\
\hline \multicolumn{3}{|l|}{ BMI Status } \\
\hline Normal weight & $2.52(1.02-6.26) *$ & $1.28(0.47-3.45)$ \\
\hline Overweight/Obese & $2.15(1.01-4.56) *$ & $2.43(1.19-4.98) *$ \\
\hline \multicolumn{3}{|l|}{ BP status } \\
\hline Normal & $2.93(1.51-5.66) * *$ & $1.55(0.81-2.95)$ \\
\hline Hypertensive & $1.35(0.32-5.66)$ & $2.81(0.67-11.80)$ \\
\hline \multicolumn{3}{|l|}{ Dyslipidaemia } \\
\hline Normal TG & $1.45(0.70-2.99)$ & $1.64(0.76-3.55)$ \\
\hline Elevated TG & $3.87(1.21-12.41) * *$ & $1.23(0.42-3.61)$ \\
\hline Normal HDL-C & $1.57(0.60-4.13)$ & $1.48(0.56-3.95)$ \\
\hline Low HDL-C & $2.95(1.40-6.24) * *$ & $2.35(1.10-5.00) *$ \\
\hline
\end{tabular}

OR-odds ratios, $P$-values are statistically significant.

$*_{\text {- } P \text {-value }}<0.05 ; * *_{\text {-P }}$-values $<0.01$

Individuals with the rs 7903146 polymorphism comparatively had higher mean TG $(\mathrm{p}=0.048)$ and high mean LDL-C in both the controls $(p=0.001)$ and cases $(p=0.046)$. Among the cases, rs7903146 SNP was associated with significantly higher mean systolic BP ( $\mathrm{p}=0.015)$ (Table S2). In table S2, those with rs12255372 SNPs, among the control group, had higher mean TG ( $p=0.003)$, TC ( $p=0.048)$, LDL-C $(\mathrm{p}=0.001)$, FPG $(\mathrm{p}=0.005)$ and HbA1c $(\mathrm{p}<0.001)$. Among the cases, $\mathrm{rs} 12255372$ polymorphism was associated with higher BMI $(\mathrm{p}=0.044)$ and systolic BP $(\mathrm{p}=0.003)$.

In Table S3, rs7903146 was significantly associated with increased odds of high LDL among the controls $(\mathrm{OR}=2.98, \mathrm{p}=0.017)$. Among the case group, individuals with the minor allele of rs7903146 were significantly associated with an increased odds ratio of high TG $(\mathrm{OR}=2.95, \mathrm{p}=0.023)$ (Table $\mathrm{S} 3)$. rs12255372 SNP was significantly associated with an increased odds ratio of high cholesterol $(\mathrm{OR}=14.0, \mathrm{p}=0.023)$ and elevated LDC-C $(\mathrm{OR}=3.12, \mathrm{p}=0.027)$ among the control group (Table $\mathrm{S} 3)$. Among the case group, rs12255372 was significantly associated with increased odds of high BP $(\mathrm{OR}=3.01, \mathrm{p}=0.013)$ and overweight/obesity $(\mathrm{OR}=3.33, \mathrm{p}=0.012)$. 


\section{Discussion}

Variants of TCFL2 gene has been consistently associated with T2DM in several studies among multiple ethnic groups $[16,21,22]$. This study demonstrated the transferability of the TCF7L2 gene polymorphisms (rs12255372 and rs7903146) and their association with T2DM among a Ghanaian population. However, the associations were observed to be relevant only in a subgroup- women, patients that do not have a family history of diabetes and those with dyslipidaemia with or without elevated blood pressure and increased BMI.

This study observed that rs7903146 and rs12255372 polymorphisms have a significant effect on T2DM, however, the effect was mediated by other diabetes risk factors. In a systematic review and Metaanalysis among a Sub-Saharan Africa (SSA) population [26], the effect of rs7903146 was 1.75 in a recessive model and 2.27 in an additive model, which is similar to our present findings. These effects are also consistent among the Caucasian, East Asian, South Asian and other ethnicities [21]. To the best of our knowledge, this study is currently among the few studies in SSA, that have demonstrated the transferability of rs12255372 [27, 28]. In contrast studies by Yako, Madubedube et al., (29) and Mandour, Darwish et al., (30), found the SNP rs12255372 to not associated with T2DM, in a South African mixed-ancestry and Egyptian population, respectively.

From a Meta-analysis by Wang, Zhang (22) among different ethnic groups, there are significant differences in the LD structure between rs 12255372 and rs7903146. From the findings of this study, weak interaction between rs12255372 and rs 7903146 for T2DM was reported (in both male and female participants). This result is similar to that observed among the Yoruba population $\left(\mathrm{D}^{\prime}=0.075, \mathrm{r}^{2}=0.001\right)$ but unlike that of the Europeans $\left(D^{\prime}=0.948, r^{2}=0.746\right)$ and Chinese $\left(D^{\prime}=0.479, r^{2}=0.114\right)$ [22].

The MAF of rs7903146 observed in this study is similar to the findings of Danquah, Othmer (15) among a Ghanaian population, where the MAF of rs7903146 was 30\% in the control population and $36 \%$ in T2DM population. Among other SSA populations, the MAF of rs7903146 among T2DM vs controls has been reported at $9.5 \%$ vs $0 \%$ in Cameroonian population [31] and $32.2 \%$ vs $24.3 \%$ in South African mixed-ancestry [29]. Furthermore, from the Allele Frequency Aggregator (ALFA) HapMap and 1000 Genomes project [32] the MAF of rs7903146 were $29.2 \%, 24.1 \%$ and $22.8 \%$, respectively, which is consistent with our findings. The race-specific risk allele frequency of rs7903146 is lower among the Asian population (range: 3.1\%-4.7\%) and higher among Europeans (29.2\%), Africans (29.5\%), African American (29.7\%), Latin American (34.2\%) and South Asians (31.8\%) [32]. A wide population difference in the minor allele frequency of rs 12255372 (Asians $=0.000$ to 0.029 , Europeans $=0.217$ 0.50 and $\mathrm{SSA}=0.267-0.274)$ has been reported [17, 30,33]. Moreover, from the results of the 1000 genomes project, the MAF of rs 12255372 is $21.4 \%$ globally, $30.2 \%$ in Africa, $29.2 \%$ among Europeans and the Americans $21.9 \%$, similar to our study. 
From the findings of this study and related literature, the association between rs12255372 and rs7903146 with T2DM are similar among West African populations, Asians, Caucasians [34, 35] and other population groups [16]. This suggests that the association of rs7903146 and rs12255372 with T2DM is moderately strong in multiple ethnicities which are likely to project a vital contribution of differences in environmental factors that confer susceptibility to T2DM.

It appears that rs12255372 and rs7903146 are not associated with T2DM among West African populations (Ghanaians and Yoruba), unlike other population groups. This finding is essential in understanding the different types and aetiology of T2DM present in SSA [36], and the wider population differences in T2DM prevalence. For example, as indicated in this study the association between rs12255372 with T2DM was relevant among women, obese/overweight individuals, individuals with negative family history, low HDL-C and individuals aged above 60 years. Similarly, rs7903146 was relevant among females, individuals with negative family history, elevated TG and low HDL-C but normal blood pressure. This indicated that TCF7L2 risk variants may be relevant to a subgroup of individuals with single or multiple diabetes risk factors, other than those with a positive family history [37].

This study observed that the risk allele rs7903146 was associated with elevated FPG and HbA1c in both the diabetic and controls. In addition to FPG and HbAlc, the risk alleles of rs 12255372 were associated with elevated BMI, blood pressure, TG and reduced LDL in T2DM and controls. This finding reflects the pleiotropic role TCF7L2 polymorphisms play in T2DM (adipogenesis, incretin and insulin expression as well as beta-cell growth and development). The rs7903146 risk alleles are associated with reduced proportional control of $\beta$-cell function among newly diagnosed T2DM patients [44]. Loos, Franks et al., (38) reported that the T-allele of rs7903146 was associated with higher HbA1c concentrations and reduced $\beta$-cell function, assessed by the homeostasis model assessment of $\beta$-cell function. TCF7L2 protein was also found to be increased during adipogenesis in 3T3-L1 cells and primary adipocyte stem cells [46] and TCF7L2 expression was required for the regulation of Wnt [39]. High expression of TCF7L2 mRNA was identified with reduced TCF7L2 protein levels in individuals with the T-allele of rs7903146, which is associated with a downregulation of GIP- and GLP-1 receptors and impaired beta-cell function Shu, Matveyenko et al., (40).

These findings suggest that TCF7L2 polymorphisms rs7903146 and rs12255372 may confer T2DM susceptibility through the expression of adipocyte-insulin resistance, delayed insulin secretion (resulting from beta-cell dysfunction) and reduced intracellular energy homeostasis. Therefore, individuals with the risk alleles of TCF7L2 (rs7903146 and rs12255372) may present with obesity, elevated TG and reduced HDL-C. Also, the findings suggest that among individuals with multiple diabetes risk factors, those who do develop T2DM may have a genetic predisposition to beta-cell dysfunction which includes the SNPs rs12255372 and rs7903146 [18]. 
Some limitations of the study are worth mentioning when interpreting the findings of this study. The differences in population substructures may result in a different interpretation of risk alleles in candidate gene association studies. Also, the number of genetic roots underlying T2DM is still being investigated and could be numerous given its multifaceted nature. Therefore, the effect of the variants among the small population considered in this study may be unpredictably low, when we consider it from a larger population. Besides this limitation, the findings of this study are consistent with the recommended approach for conducting a candidate gene association study and present consistent findings with similar studies among other population groups.

\section{Materials and Methods}

This case-control study was conducted at the Begoro District Hospital (BDH) and two communities (Bosuso and Begoro) in the Eastern Region of Ghana. The study included participants aged 30-79 years. Cases were defined as clinically diagnosed T2DM patients attending the diabetic clinic at the BDH. Controls were defined as non-diabetic patients with normal fasting plasma glucose (FPG) and/or normal $\mathrm{HbA1C}$ that voluntarily participated in a health screening program conducted as part of the study in Bosuso or Begoro. Participants willing to have their body mass index (BMI), FPG, HbAlc and lipid profile checked and provided written informed consent during the health screening were recruited as controls. Control participants with a self-reported, previous or current, history of renal, liver, thyroid disorders or other endocrine diseases, chronic diseases, on hormone replacement therapy or corticosteroid therapy were excluded from the study. T2DM patients who self-managed or being managed for micro-vascular or macrovascular complications were excluded from the study.

\section{Sample Size Calculation}

Taking the minor allele frequency (MAF) of the lead SNP rs7903146 from a previous study [15], at a patient-to-control ratio of $1: 1$, at $95 \% \mathrm{CI}$, and $6 \%$ proportional differences $\left(\mathrm{P}^{*}=(0.36+0.30) / 2=0.33\right.$; $(\mathrm{P} 1-\mathrm{P} 2)=(0.36-0.30)=0.06$, the minimum recommended sample size at $80 \%$ power replication under Kelsey method [41] were 100 cases and 100 controls. Overall, 106 T2DM and 110 non-diabetic controls met the inclusion criteria.

\section{Recruitment Process}

The control participants were recruited during a health screening program conducted in the two communities. Additional controls were sorted through community members that were informed via the various religious organizations. Initially, the intent, preparation and benefits of the health screening program was announced in all the religious-based organisations. The health screening process took place every morning (Monday, Wednesday and Friday) from 8:00 am to 11:30 am from May 2019 to November 2019. T2DM patients were recruited using a total sampling method. All patients that visited the BDH hospital during the study period and met the inclusion criteria were considered as a sample. 
Blood pressure measurement was taken using an automated sphygmomanometer (Omron BP7200, Omron Healthcare, Inc., USA). Three different measurements were taken at 5-minute intervals and the average was used as the final reading. All blood pressure recordings were done in $\mathrm{mmHg}$.

The Omron B511 (Omron Healthcare, Inc., USA) was used for weight measurement, following the manufacturer's instruction. Briefly, participants were asked to stand in upright on the main unit of the scale and without shoes. Portable Height Rod Stadiometers (QuickMedical, Warwick) were used for body height; the subject stood upright, with feet together and flat on the ground. BMI was calculated as the ratio of weight to height-squared $\left(\mathrm{Kg} / \mathrm{m}^{2}\right)$.

Six millilitres $(\mathrm{ml})$ of venous blood were taken in a fasting state and two millilitres each were placed into sterile ethylene diamine tetraacetic acid (EDTA) (BD Vacutainer ${ }^{\circledR}$, USA), gel separator and Sodium Fluoride/Calcium oxalate tubes (BD Vacutainer ${ }^{\circledR}$, USA). Fasting was defined as no caloric intake for at least $8 \mathrm{~h}$, overnight. The EDTA samples were used for HbA1c analysis using standard A1cCare System (SD BIOSENSOR, republic of Korea). The remaining EDTA sample was used for DNA extraction and consequent SNPs genotyping. The gel separator tubes samples were processed by centrifugation at $3,000 \mathrm{rpm}$ for 10 minutes and the serum was collected into $1.5 \mathrm{ml}$ eppendorf tubes. The obtained sera were used for lipid profiling. The plasma obtained from the Sodium Fluoride/Calcium oxalate tube samples was used for the determination of Fasting Plasma Glucose (FPG).

\section{Biochemical Measurements and Definition of Cardiometabolic risk factors}

The Lipid and FPG analysis were conducted at the Eastern Regional Hospital's Clinical Chemistry laboratory, using the SELECTRAPRO M chemistry analyser (EliTechGroup B.V, Netherlands). All analysis was recorded in mmol/l. The lipid profile included HDL-C, low-density lipoprotein cholesterol (LDL-C) and TG and total cholesterol (TC)

Dyslipidaemia was defined as follows: high TC $(>5.0 \mathrm{mmol} / 1)$, high LDL-C $(>3.0 \mathrm{mmol} / \mathrm{l})$, high TG $(>1.7 \mathrm{mmol} / 1)$, low HDL-C $(<1.0 \mathrm{mml} / 1$ for men and $<1.2 \mathrm{mmol} / 1$ for women) [42]. Atherogenic dyslipidaemia was defined as high TG levels, low HDL cholesterol levels and an increase in small dense LDL [43]. BMI was categorized into four groups according to the conventional WHO classification [44]: underweight $\left(<18.5 \mathrm{~kg} / \mathrm{m}^{2}\right)$, normal weight (18.5-24.9 kg/m²), overweight $\left(25-29.9 \mathrm{~kg} / \mathrm{m}^{2}\right)$, and obese ( $\geq 30 \mathrm{~kg} / \mathrm{m}^{2}$ ). Metabolic syndrome (MetS) was defined according to the National Cholesterol Education Program (NCEP) Adult Treatment Panel III (ATP III), without waist circumference [45]; BP over 130/85 mmHg, TG > $1.7 \mathrm{mmol} / \mathrm{l}$, HDL-C levels less than $1.03 \mathrm{mmol} / \mathrm{l}$ (men) or $1.29 \mathrm{mmol} / \mathrm{l}$ (women) and fasting blood sugar over $5.5 \mathrm{mmol} / \mathrm{l}$ (Table 5). 
Table 5: Definition of metabolic syndrome

\begin{tabular}{|c|c|c|}
\hline Component & Standard criteria [45] & Criteria used in the present study \\
\hline $\begin{array}{l}\text { Elevated waist } \\
\text { circumference }\end{array}$ & $\begin{array}{l}\text { Population- and country-specific } \\
\text { definitions }\end{array}$ & $\mathrm{BMI} \geq 30 \mathrm{~kg} / \mathrm{m}^{2}$ \\
\hline Elevated TG & $\begin{array}{l}\mathrm{TG} \geq 150 \mathrm{mg} / \mathrm{dL}(1.7 \mathrm{mmol} / \mathrm{L}), \text { or } \\
\text { drug treatment }\end{array}$ & Fasting TG $\geq 150 \mathrm{mg} / \mathrm{dl}(1.7 \mathrm{mmol} / \mathrm{L})$ \\
\hline Reduced HDL-C & $\begin{array}{l}\mathrm{HDL}-\mathrm{C}<40 \mathrm{mg} / \mathrm{dL}(1.0 \mathrm{mmol} / \mathrm{L}) \\
\text { in males; HDL-C }<50 \mathrm{mg} / \mathrm{dl} \\
(1.3 \mathrm{mmol} / \mathrm{L}) \text { in females; or drug } \\
\text { treatment }\end{array}$ & $\begin{array}{l}\text { HDL-C }<40 \mathrm{mg} / \mathrm{dl}(1.0 \mathrm{mmol} / \mathrm{L}) \text { in males } \\
\text { HDL-C }<50 \mathrm{mg} / \mathrm{dl}(1.3 \mathrm{mmol} / \mathrm{L}) \text { in females }\end{array}$ \\
\hline $\begin{array}{l}\text { Elevated blood } \\
\text { pressure }\end{array}$ & $\begin{array}{l}\text { Systolic } \geq 130 \text { and/or diastolic } \\
\geq 85 \mathrm{mmHg}, \text { or drug treatment }\end{array}$ & Systolic $\geq 130$ and/or diastolic $\geq 85 \mathrm{mmHg}$ \\
\hline Elevated glucose & $\begin{array}{l}\geq 100 \mathrm{mg} / \mathrm{dL} \text { in plasma, or drug } \\
\text { treatment }\end{array}$ & $\begin{array}{l}\text { Fasting blood glucose } \geq 100 \mathrm{mg} / \mathrm{dL} \\
(5.5 \mathrm{mmol} / \mathrm{L}) \text { and/or } \\
\text { T2DM based on hospital records }\end{array}$ \\
\hline
\end{tabular}

\section{Genomic DNA Extraction}

Genomic DNA was extracted using a modified, simplified non-enzymatic salting-out method (details are shown in supplementary material). Briefly, $300 \mathrm{ul}$ of whole blood was used from each of the 24 samples resulting in good quality of DNA with the concentration ranging between 60 to $>100 \mathrm{ng} / \mu \mathrm{l}$ being extracted. The results of 1\% (w/v) Agarose gel and Thermo Scientific ${ }^{\mathrm{TM}}$ NanoDrop 2000 full spectrum of the product are presented in Figure S1 and S2.

\section{Primer design and primer information}

Based on the GenBank sequence of human TCF7L2 the sequence surrounding the SNPs rs7903146 (NG_012631.1:g.53341) and rs12255372 (NG_012631.1:g.10389) was obtained. Two sets of primers for modified tetra-primer amplification assay (MTPA) PCR were designed using web-based software (http://sci.ui.ac.ir/*rahgozar). Several pairs of primers were identified and further refined using PrimerBLAST (http://www.ncbi.nlm.nih.gov/blast ) and Oligo-Analyzer 3.1 IDT (https://www.idtdna.com/calc/analyzer). The primers used are provided in Table 6. 
Table 6: Primers and Concentration of reagents

\begin{tabular}{|c|c|c|c|c|}
\hline SNP & Primer name & Primer Sequence (5'->3') & $\begin{array}{c}\text { Melting } \\
\text { Temp }\end{array}$ & $\begin{array}{c}\text { Product } \\
\text { (BP) }\end{array}$ \\
\hline rs 7903146 & FIP (T allele) & TAGAGAGCTAAGCACTTTTTAGA $\underline{\text { GAT }}$ & 57.5 & 395 \\
\hline rs7903146 & RIP (C allele) & GCCTCATACGGCAATTAAATTATA $\underline{\text { GAG }}$ & 58.3 & 285 \\
\hline rs7903146 & FOP & 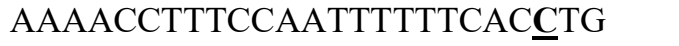 & 57.5 & 628 \\
\hline rs 7903146 & ROP & ATCCATCCACAAGCTAACCCCT & 59.1 & 628 \\
\hline rs 12255372 & FIP (T allele) & CCAGGAATATCCAGGCAAGA $\underline{\mathbf{T T}} \underline{\mathbf{G}}$ & 55.8 & 171 \\
\hline rs 12255372 & RIP (C allele) & GGCCTGAGTAATTATCAGAATATGㅡTㅡㅡ & 58.3 & 106 \\
\hline rs 12255372 & FOP & GTCCCTTGAGGTGTACTGㅡAAA & 56.7 & 228 \\
\hline rs 12255372 & ROP & TATTTGGCATTCAAATGGACGGC & 55.0 & 228 \\
\hline
\end{tabular}

FIP-forward inner primer; RIP-reverse inner primer; FOP; forward outer primer; ROP: reverse outer primer; Tm- melting temperature; Ta- annealing temperature

\section{Genotyping of TCF7L2 rs7903146 and rs12255372}

Each $25 \mu \mathrm{L}$ reaction mixture contained 1X of OneTaq ${ }^{\circledR} 2 \mathrm{X}$ Master Mix (New England Biolabs), 0.2 $\mu \mathrm{M}$ each of forward and reverse primers and $>50 \mathrm{ng}$ of DNA. Incubation of the $25 \mu \mathrm{L}$ reaction mixture was completed at $94^{\circ} \mathrm{C}$ for 5 minutes, followed by 30 cycles of 30 -sec denaturation $\left(94^{\circ} \mathrm{C}\right), 1 \mathrm{~min}$ annealing $\left(57.7^{\circ} \mathrm{C}\right.$ for $\mathrm{rs} 7903146$ or $55.0^{\circ} \mathrm{C}$ for $\left.\mathrm{rs} 12255372\right), 30$-sec extension $\left(72^{\circ} \mathrm{C}\right)$ and additional 10 minutes extension at $72^{\circ} \mathrm{C}$ at the end of the 30 cycles. The final product was visualised with $1.5 \%(\mathrm{w} / \mathrm{v})$ of agarose gel electrophoresis alongside a 100-base pair (bp) marker with Ethidium bromide stain (Figure S3 and S4). For quality control and troubleshooting see supplementary appendix (Table S1).

\section{Data Analysis}

Analysis of the data was conducted using SPSS version 25. Normality of continues data was checked using the Kolmogorov Simonov test. Descriptive statistics were reported using frequencies for categorical data and mean for continues data. Chi-square test was used to evaluate the independence of the categorical data and t-test for the continues data between cases and controls. To test for associations between T2DM phenotype and all SNPs, logistic regression models were fitted, in which each SNP was presented as a predictor variable whose values were equal to the number of copies of the minor allele $(0,1,2)$ in an additive model, or presence of at least one copy of the minor allele $(0,1)$ in a codominant model or presence of two copies of the minor allele $(0,1)$ in a recessive model. Sex, age and family history were included as covariates in the fitted model. The structure of the model was represented as:

$\operatorname{Logit}[\operatorname{pr}(D=1)]=\alpha+\beta_{1} G+\beta_{2} \operatorname{sex}_{(\text {male })}+\beta_{3}$ age $(\geq 60$ years $)+\beta_{\text {positive family history }}+\beta$ high cholesterol $\beta$ 
To examine the associations between T2DM phenotype and various allelic configurations of rs7903146 and rs12255372, haplotype association analysis was performed. The statistical analyses for linkage disequilibrium (LD), haplotype frequencies, and multiple test corrections per 1000 random permutations were performed using the Haploview 4.2 software $[46,47]$. The haplotype blocks were defined by the four-gamete test [48, 49] as implemented in Haploview. A weak interaction between rs7903146 and rs12255372 was observed, data not shown. Univariate models adjusted for age and gender, these were used to evaluate the association between the SNPs and cardiometabolic markers. Pvalues $<0.05$ were considered statistically significant.

\section{Conclusion}

There is a relatively high prevalence of the risk alleles of TCF7L2 (rs7903146 and rs12255372) among the Ghana population with a modest association with T2DM. The association between rs7903146 and rs 12255372 with T2DM may be relevant in a subgroup of individuals (women), particularly those with no family history of diabetes and those with cardiometabolic risk with or without elevated blood pressure. Therefore, genotyping of these SNPs is essential for future multi-ethnic association studies and clinically significant for classifying high-risk patients.

\section{Supporting Information}

Figure S1: 1\% agarose gel electrophoresis of genomic DNA extracted from MSO method

Figure S2: A typical Nanodrop curve of absorbance against the path of light travel (wavelength) of DNA samples

Figure S3: 2\% agarose gel electrophoresis of TCF7L2- rs7903146

Figure S4: 2\% agarose gel electrophoresis of TCF7L2-rs12255372

Table S1: Master mix recipe for genotyping quality control

Table S2: Association of rs7903146 with Anthropometric and biochemical markers among the control and case groups

Table S3: Association of rs7903146 with cardiometabolic risk factors among the control and case groups

Table S4: Association of rs12255372 with Anthropometric and biochemical markers among the control and case groups

Table S5: Association of rs12255372 with cardiometabolic risk factors among the control and case groups

\section{Acknowledgements}

The authors acknowledge the management of the Begoro District Hospital and the Eastern Regional Hospital, especially Mary Koryoe Tetteh (Head of Laboratory Department, BDH) and Aaron Siaw Kwakye, for their support and vital contribution to the work 


\section{Author Contributions}

Conceptualization, CO, WW, LB; Methodology, CO, EAA, EA, MEAA, EO, LQ, BYA; Validation, LQ, WW, and LB; Formal Analysis, EAA, EAY; Investigation, CO, EAA, EA, ASK, FF.; Resources, MA, ENYN, FA, CO, EA, MEAA; Data Curation, EAA, ASK, FF; Writing - Original Draft Preparation, EAA.; Writing - Review \& Editing, CO, EAA, EO, MEAA, EA, LQ, BYA, WW, LB; Supervision, CO. All authors read and approved the manuscript before submission.

\section{Conflict of Interest}

The authors declare that they have no conflict of interest

\section{Funding}

The study did not receive any funding

\section{Ethical policy}

The study was conducted according to the guidelines of the Declaration of Helsinki and approved by the Committee on Human Research, Publications and Ethics (CHRPE), School of Medicine and Dentistry (SMD), Kwame Nkrumah University of Science and Technology (CHRPE/AP/034/20). Written informed consent was obtained from all subjects involved in the study.

\section{Data Availability Statement}

All data supporting the conclusions of this study are summarized in Tables and supplementary materials. The raw data is available from the corresponding author upon reasonable request.

\section{References}

1. IDF IDF. IDF Diabetes Atlas 8th Edition (2017). 2017.

2. Khan MAB, Hashim MJ, King JK, Govender RD, Mustafa H, Al Kaabi J. Epidemiology of Type 2 Diabetes - Global Burden of Disease and Forecasted Trends. J Epidemiol Glob Health. 2020;10(1):107-11.

3. da Rocha Fernandes J, Ogurtsova K, Linnenkamp U, Guariguata L, Seuring T, Zhang P, et al. IDF Diabetes Atlas estimates of 2014 global health expenditures on diabetes. Diabetes Res Clin Pract. 2016;117:48-54.

4. Hudspeth B. The burden of cardiovascular disease in patients with diabetes. Am J Manag Care. 2018;24(13 Suppl):S268-S72.

5. Beagley J, Guariguata L, Weil C, Motala AA. Global estimates of undiagnosed diabetes in adults. Diabetes Res Clin Pract. 2014;103(2):150-60.

6. Asamoah-Boaheng M, Sarfo-Kantanka O, Tuffour AB, Eghan B, Mbanya JC. Prevalence and risk factors for diabetes mellitus among adults in Ghana: a systematic review and meta-analysis. International Health. 2018;11(2):83-92.

7. Issaka A, Paradies Y, Stevenson C. Modifiable and emerging risk factors for type 2 diabetes in Africa: a systematic review and meta-analysis protocol. Systematic Reviews. 2018;7(1):139. 
8. Meigs JB, Cupples LA, Wilson P. Parental transmission of type 2 diabetes: the Framingham Offspring Study. Diabetes. 2000;49(12):2201-7.

9. Poulsen P, Kyvik KO, Vaag A, Beck-Nielsen H. Heritability of type II (non-insulindependent) diabetes mellitus and abnormal glucose tolerance-a population-based twin study. Diabetologia. 1999;42(2):139-45.

10. Zaman GS. Pathogenesis of Insulin Resistance. Cellular Metabolism and Related Disorders: IntechOpen; 2020.

11. Herman MA, Kahn BB. Glucose transport and sensing in the maintenance of glucose homeostasis and metabolic harmony. The Journal of clinical investigation. 2006;116(7):176775 .

12. Qi L, Cornelis MC, Kraft P, Stanya KJ, Linda Kao W, Pankow JS, et al. Genetic variants at $2 \mathrm{q} 24$ are associated with susceptibility to type 2 diabetes. Hum Mol Genet. 2010;19(13):2706-15.

13. Morris AP, Voight BF, Teslovich TM, Ferreira T, Segre AV, Steinthorsdottir V, et al. Large-scale association analysis provides insights into the genetic architecture and pathophysiology of type 2 diabetes. Nat Genet. 2012;44(9):981.

14. Cauchi S, El Achhab Y, Choquet H, Dina C, Krempler F, Weitgasser R, et al. TCF7L2 is reproducibly associated with type 2 diabetes in various ethnic groups: a global meta-analysis. J Mol Med. 2007;85(7):777-82.

15. Danquah I, Othmer T, Frank LK, Bedu-Addo G, Schulze MB, Mockenhaupt FP. The TCF7L2 rs7903146 (T) allele is associated with type 2 diabetes in urban Ghana: a hospitalbased case-control study. BMC Med Genet. 2013;14(1):96.

16. Dieudonne N, Sobngwi E, Atogho-Tiedeu B, Noubiap JJ, Donfack O, Mato-Mofo E, et al. Association between the TCF7L2 rs12255372 (G/T) gene polymorphism and type 2 diabetes mellitus in a Cameroonian population: a pilot study. Clinical and Translational Medicine. $2015 ; 4$.

17. Huang Z-q, Liao Y-q, Huang R-z, Chen J-p, Sun H-1. Possible role of TCF7L2 in the pathogenesis of type 2 diabetes mellitus. Biotechnology \& Biotechnological Equipment. 2018;32(4):830-4.

18. Katsoulis K, Paschou SA, Hatzi E, Tigas S, Georgiou I, Tsatsoulis A. TCF7L2 gene variants predispose to the development of type 2 diabetes mellitus among individuals with metabolic syndrome. Hormones. 2018;17(3):359-65.

19. Shu L, Sauter NS, Schulthess FT, Matveyenko AV, Oberholzer J, Maedler K. Transcription factor 7-like 2 regulates $\beta$-cell survival and function in human pancreatic islets. Diabetes. 2008;57(3):645-53.

20. Grant SF, Thorleifsson G, Reynisdottir I, Benediktsson R, Manolescu A, Sainz J, et al. Variant of transcription factor 7-like 2 (TCF7L2) gene confers risk of type 2 diabetes. Nat Genet. 2006;38(3):320.

21. Ding W, Xu L, Zhang L, Han Z, Jiang Q, Wang Z, et al. Meta-analysis of association between TCF7L2 polymorphism rs7903146 and type 2 diabetes mellitus. BMC Med Genet. 2018;19(1):38-.

22. Wang J, Zhang J, Li L, Wang Y, Wang Q, Zhai Y, et al. Association of rs 12255372 in the TCF7L2 gene with type 2 diabetes mellitus: a meta-analysis. Brazilian journal of medical and biological research $=$ Revista brasileira de pesquisas medicas e biologicas. 2013;46(4):38293.

23. Lyssenko V, Lupi R, Marchetti P, Del Guerra S, Orho-Melander M, Almgren P, et al. Mechanisms by which common variants in the TCF7L2 gene increase risk of type 2 diabetes. The Journal of clinical investigation. 2007;117(8):2155-63. 
24. Ip W, Chiang Y-TA, Jin T. The involvement of the wnt signaling pathway and TCF7L2 in diabetes mellitus: The current understanding, dispute, and perspective. Cell Biosci. 2012;2(1):28-.

25. Wu H-H, Li Y-L, Liu N-J, Yang Z, Tao X-M, Du Y-P, et al. TCF7L2 regulates pancreatic $\beta$-cell function through PI3K/AKT signal pathway. Diabetol Metab Syndr. 2019;11(1):55.

26. Asamoah EA, Obirikorang C, Acheampong E, Annani-Akollor ME, Laing EF, Owiredu E-W, et al. Heritability and Genetics of Type 2 Diabetes Mellitus in Sub-Saharan Africa: A Systematic Review and Meta-Analysis. Journal of diabetes research. 2020;2020.

27. Helgason A, Pálsson S, Thorleifsson G, Grant SF, Emilsson V, Gunnarsdottir S, et al. Refining the impact of TCF7L2 gene variants on type 2 diabetes and adaptive evolution. Nat Genet. 2007;39(2):218.

28. Nanfa D, Sobngwi E, Atogho-Tiedeu B, Noubiap JJN, Donfack OS, Mofo EPM, et al. Association between the TCF7L2 rs $12255372(\mathrm{G} / \mathrm{T})$ gene polymorphism and type 2 diabetes mellitus in a Cameroonian population: a pilot study. Clinical and translational medicine. 2015;4(1):17.

29. Yako YY, Madubedube JH, Kengne AP, Erasmus RT, Pillay TS, Matsha TE. Contribution of ENPP1, TCF7L2, and FTO polymorphisms to type 2 diabetes in mixed ancestry ethnic population of South Africa. Afr Health Sci. 2015;15(4):1149-60.

30. Mandour I, Darwish R, Fayez R, Naguib M, El-Sayegh S. TCF7L2 Gene Polymorphisms and Susceptibility to Type 2 Diabetes Mellitus, a Pilot Study. Biomedical and Pharmacology Journal. 2018;11(2):1043-9.

31. Guewo-Fokeng M, Sobngwi E, Atogho-Tiedeu B, Donfack OS, Noubiap JJN, Ngwa $\mathrm{EN}$, et al. Contribution of the TCF7L2 rs7903146 (C/T) gene polymorphism to the susceptibility to type 2 diabetes mellitus in Cameroon. Journal of Diabetes \& Metabolic Disorders. 2015;14(1):26.

32. Clark K, Karsch-Mizrachi I, Lipman DJ, Ostell J, Sayers EW. GenBank. Nucleic Acids Res. 2016;44(D1):D67-D72.

33. Lehman DM, Hunt KJ, Leach RJ, Hamlington J, Arya R, Abboud HE, et al. Haplotypes of transcription factor 7-like 2 (TCF7L2) gene and its upstream region are associated with type 2 diabetes and age of onset in Mexican Americans. Diabetes. 2007;56(2):389-93.

34. Li Y-y, Yang X-x, Geng H-y, Gong G. Type 2 diabetes mellitus and TCF7L2 gene rs 12255372 G/T polymorphism: a meta-analysis involving 7990 subjects. Int J Diabetes Dev Ctries. 2018;38(1):55-61.

35. Xi X, Ma J. A meta-analysis on genetic associations between Transcription Factor 7 Like 2 polymorphisms and type 2 diabetes mellitus. Genomics. 2020;112(2):1192-6.

36. Kibirige D, Lumu W, Jones AG, Smeeth L, Hattersley AT, Nyirenda MJ. Understanding the manifestation of diabetes in sub Saharan Africa to inform therapeutic approaches and preventive strategies: a narrative review. Clinical Diabetes and Endocrinology. 2019;5(1):2.

37. Wunsch C, Dornelles TF, Girardi P, Arndt ME, Genro JP, Contini V. Lack of association between TCF7L2 gene variants and type 2 diabetes mellitus in a Brazilian sample of patients with the risk for cardiovascular disease. Endocr Regul. 2019;53(1):1-7.

38. Loos RJ, Franks PW, Francis RW, Barroso I, Gribble FM, Savage DB, et al. TCF7L2 polymorphisms modulate proinsulin levels and $\beta$-cell function in a British Europid population. Diabetes. 2007;56(7):1943-7.

39. Chen X, Ayala I, Shannon C, Fourcaudot M, Acharya NK, Jenkinson CP, et al. The Diabetes Gene and Wnt Pathway Effector TCF7L2 Regulates Adipocyte Development and Function. Diabetes. 2018;67(4):554-68. 
40. Shu L, Matveyenko AV, Kerr-Conte J, Cho J-H, McIntosh CH, Maedler K. Decreased TCF7L2 protein levels in type 2 diabetes mellitus correlate with downregulation of GIP-and GLP-1 receptors and impaired beta-cell function. Hum Mol Genet. 2009;18(13):2388-99.

41. Kelsey JL, Whittemore AS, Evans AS, Thompson WD. Methods in observational epidemiology: Monographs in Epidemiology and Biostatistics; 1996.

42. Graham I, Atar D, Borch-Johnsen K, Boysen G, Burell G, Cifkova R, et al. European guidelines on cardiovascular disease prevention in clinical practice: executive summary: Fourth Joint Task Force of the European Society of Cardiology and Other Societies on Cardiovascular Disease Prevention in Clinical Practice (Constituted by representatives of nine societies and by invited experts). Eur Heart J. 2007;28(19):2375-414.

43. Semenkovich CF. Insulin resistance and atherosclerosis. $J$ Clin Invest. 2006;116(7):1813-22.

44. WHO EP. Executive summary of the clinical guidelines on the identification, evaluation, and treatment of overweight and obesity in adults. Arch Intern Med. 1998;158:1855-67.

45. Grundy SM, Cleeman JI, Daniels SR, Donato KA, Eckel RH, Franklin BA, et al. Diagnosis and management of the metabolic syndrome: an American Heart Association/National Heart, Lung, and Blood Institute Scientific Statement. Circulation. 2005;112(17):2735-52.

46. Barrett JC, Fry B, Maller J, Daly MJ. Haploview: analysis and visualization of LD and haplotype maps. Bioinformatics. 2004;21(2):263-5.

47. Devlin B, Risch N. A comparison of linkage disequilibrium measures for fine-scale mapping. Genomics. 1995;29(2):311-22.

48. Hudson RR, Kaplan NL. Statistical properties of the number of recombination events in the history of a sample of DNA sequences. Genetics. 1985;111(1):147-64.

49. Wang N, Akey JM, Zhang K, Chakraborty R, Jin LJTAJoHG. Distribution of recombination crossovers and the origin of haplotype blocks: the interplay of population history, recombination, and mutation. The American Journal of Human Genetics. 2002;71(5):1227-34. 